\title{
MAF moves higher and faster
}

\author{
David J S Birch ${ }^{1}$, Marcia Levitus² and Yves Mély ${ }^{3}$ \\ ${ }^{1}$ The Photophysics Research Group, University of Strathclyde, Department of Physics, SUPA, John \\ Anderson Building, 107 Rottenrow, Glasgow, G4 ONG, United Kingdom
}

${ }^{2}$ School of Molecular Sciences and The Biodesign Institute, Arizona State University, PO Box 875601, Tempe AZ, 85287-5601, USA.

\footnotetext{
${ }^{3}$ Laboratoire de Bioimagerie et Pathologies, UMR7021 CNRS, Faculté de Pharmacie, Université de Strasbourg, Cedex, 67401 Illkirch, France
}

E-mail: djs.birch@strath.ac.uk

Dear Readers

In last year's Editorial [1] we highlighted the fluorescence-leading Impact Factor of Methods and Applications in Fluorescence (MAF) and in this $10^{\text {th }}$ anniversary year of the founding of $M A F$ we are delighted to report the journal has further increased its citation count, achieving the key milestone of Impact Factor 3. Hand in hand with this progress and of good news for authors submitting to the journal is that the median submission time to first decision after peer review has fallen from 55 to 35 days. The diligent work of authors, reviewers, Institute of Physics Publishing and the Editorial Board has made this significant progress possible and we offer our sincere thanks for their important contributions.

Studying the content of MAF over the past year reveals how the journal continues to publish only the highest quality work in fluorescence. In 2021 the journal published six Topical Reviews, three of them with already well over 1000 downloads. These were Navigating across multi-dimensional space of tissue clearing parameters by Sergiy Avilov [2], Understanding DNA organization, damage, and repair with super-resolution fluorescence microscopy by Esther Miriklis et al [3] and Fluorescence Guided Surgery by Hazel Stewart and David Birch [4].

The first paper in the UPCON Special Issue has now been published [5] and looking to the year ahead an exciting programme of Special Issues is already in the making. This includes Fluorescence Research in India edited by Sudipta Maiti and Vineet Rai, A Celebration of the work of Enrico Gratton edited by Michelle Digman, Women in Fluorescence edited by Catherine Royer and Ute RenschGenger, Fluorescent organic nanoparticles edited by Bo Laursen and a compilation of 12 articles in Emerging Leaders in Fluorescence.

We warmly invite researchers from across all disciplines that use fluorescence to submit their latest work to $M A F$ and benefit from its high impact and speed to publication. 
Looking beyond the journal all of us in the fluorescence community hope we can at last get together in Gothenburg in September for the postponed MAF conference. We very much hope to see you there. Until then, our very best wishes to you all for a happy and successful 2022.

\section{References}

1. MAF and fluorescence play their part

David J S Birch, Marcia Levitus and Yves Mély. 2021 Methods Appl. Fluoresc. 9010401

2. Navigating across multi-dimensional space of tissue clearing parameters Sergiy V Avilov. 2021 Methods Appl. Fluoresc. 9022001

3. Understanding DNA organization, damage, and repair with super-resolution fluorescence microscopy Esther L Miriklis, Ashley M Rozario, Eli Rothenberg, Toby D M Bell and Donna R Whelan. 2021 Methods Appl. Fluoresc. 9032002

4. Fluorescence Guided Surgery Hazel L Stewart and David J S Birch. 2021 Methods Appl. Fluoresc. 9042002

5. A first approach to the use of upconversion nanoparticles to measure fluorescent tracers in water: a proof of concept

Juan M Bujjamer, Marcos Illescas, M Claudia Marchi, Hernán E Grecco and Beatriz C Barja. 2021 Methods Appl. Fluoresc. 9044001 